\title{
THE CONNECTION OF THE VOMERONASAL NERVES WITH THE ACCESSORY OLFACTORY BULB IN THE OPOSSUM AND OTHER MAMMALS
}

\author{
ROLLO E. MCCOTTER \\ From the Anatomical Laboratory, University of Michigan, Ann Arbor \\ SEVEN FIGURES
}

It is well known that there exists in most mammals an accessory olfactory bulb, which is similar in structure and in its peripheral and central connections to the chief olfactory bulb, though it is much smaller and is distinctly separated from it. On the other hand, it has been clearly shown that the vomeronasal or Jacobson's organ is olfactory in character and that it gives origin to nerve filaments, like those of the olfactory mucosa, which form bundles that pass upward through the cribriform plate to the region of the median surface of the olfactory bulb. It has not, however, been recognized, as far as the writer knows, that the fibers arising from the vomeronasal organ and the fibers connected with the accessory bulb are one and the same thing. It is the purpose of the present paper to report some observations which establish this connection, and which show that we have in the vomeronasal nerves the combined filaments from the vomeronasal organ, and that they are the fibers that terminate in the accessory olfactory bulb and are the only fibers it receives. We thus have in the accessory olfactory bulb a receptive station for the stimuli coming from the mucosa of the vomeronasal organ.

The writer's attention was turned toward this subject in the course of an investigation of the olfactory apparatus of the 
opossum which he has undertaken as a part of a general study of the central nervous system of this animal that is being carried on in this laboratory. In tracing the origin and distribution of the olfactory nerve filaments it gradually became apparent that a special group of fibers could be isolated that arose in the vomeronasal organ and terminated in the accessory bulb. A subsequent examination of other mammals showed that a similar condition existed in the rodent group, the ungulates, the cat and the dog. In all of them the vomeronasal nerve filaments exhibit a characteristic difference from the olfactory filaments both in their course, size and termination. Before reporting my own observations in detail I will briefly review the literature concerning this region so far as it has come to my notice.

Apparently from the first it was supposed that Jacobson's or the vomeronasal organ was olfactory in character. It was early shown by Balogh ('60), Klein ('81 a) and Piana ('82) that its mucosa contained neuroepithelial cells like those found in the olfactory mucosa. Subsequently v. Brunn ('92) and Lenhossék ('92) demonstrated that these cells gave origin to axones that passed upward in the nasal submucosa of the septum like the olfactory nerve filaments. Read ('08) confirmed these observations and carefully traced the course of these fibers from Jacobson's organ through the cribriform plate to the region of the median surface of the olfactory bulb. Following the terminology of DeVries ('05) she used the words ' nervus vomeronasalis' as including the whole group, thereby distinguishing them from the ordinary olfactory fibers.

The existence of the accessory olfactory bulb in mammals was first recognized by v. Gudden ('70). He described it in the rabbit as a slightly elevated oval body, lying on the olfactory peduncle posterior to the olfactory bulb, which in structure resembles the olfactory bulb, like the latter receiving olfactory filaments and giving off fibers to the lateral olfactory tract. Ganser ('82) reports an accessory olfactory bulb in the mole. He describes it as smaller than that in the rabbit, but as in the rabbit it is similar in structure and lamination to the olfactory 
bulb. Koelliker ('96) was the first writer to illustrate the structure and relations of the accessory olfactory bulb. In his Gewebelehre he shows a transverse Wiegert stained section through the olfactory bulb of the rabbit which clearly shows the relation between the accessory olfactory bulb and the main olfactory formation. Ziehen ('97) mentions a structure in marsupials (Pseudochirus) similar to that described by Gudden in the rabbit, wedged in between the olfactory bulb and olfactory peduncle at the dorsomedian angle. Cajal ('11) describes the accessory olfactory bulb of the mouse, rabbit and guinea pig as a circular structure situated on the superior surface of the olfactory bulb. It is hemispherical in shape and in cross section semilunar. A special bundle of olfactory fibers reaches it by coursing transversely and terminates by loose arborizations within the glomeruli. According to his description there are no true mitral cells present but in their places he describes triangular and stellate cells of small and medium size whose dendrites pass outward and terminate in loose arborizations. The axis cylinders pass to the thin layer of fibers that lie beneath and go to the lateral olfactory tract. A layer of granules lies below the latter and resembles the granules of the olfactory bulb but are much smaller.

There are three important papers to which special attention should be directed as they directly cover the work with which we are involved. The first of these is by Balogh ('60) whose valuable contribution has been unduly overlooked by most writers. He clearly traced in the sheep filaments arising from the median surface of Jacobson's organ which pass upward to the cribriform plate in three or four well defined bundles. After entering the cranium by a single foramen the single trunk thus formed turns lateralward to terminate in 'Jacobson's hill.' Judging from the figures (12 to 14) accompanying his paper the structure he named as 'Jacobson's hill' is plainly what we now know to be the accessory olfactory bulb. He recognized and successfully traced the fibers from Jacobson's organ to their termination, but the histological character and the central connections of his Jacobson's hill were of course unknown to him. 
In 1897 G. Elliot Smith described the olfactory bulb of a foetal ornithorhynchus. He speaks of it as imperfectly covered by two distinct ganglionic masses. The larger median mass covered the median surface and extended onto the dorsal and ventral surfaces. It received the terminations of the olfactory nerves. He called this the 'olfactory' ganglion. On the lateral aspect of the bulb is the smaller mass which receives the terminations of the nerves arising from Jacobson's organ. This mass he termed the 'ganglion of Jacobson's organ.' It seems very probable that his ganglion of Jacobson's organ was the same thing as Balogh's Jacobson's hill and that he had before him the embryonic accessory olfactory bulb.

The third paper is by Döllkin ('09) who studied Cajal preparations of very young embryos of man, rabbit and mouse. DeVries ('05) had previously studied the human embryo and had concluded that the vomeronasal nerves were the same thing as the nervus terminalis found in lower forms. Döllkin's material was more abundant than DeVries' and his results more definite. He successfully traced the nerves from the vomeronasal organ to a ganglionic mass on the oral extremity of the hemisphere which he termed the 'ganglion terminale.' As the stages with which he worked were before the formation of the olfactory bulb, he did not clearly determine the relation of the ganglion terminale to the olfactory bulb on the one hand or the preterminal area on the other. He concluded, however, that it was connected with the latter area and agreed with DeVries in believing that the vomeronasal nerve and the nervus terminalis were the same thing. He shows ganglion cells scattered along the course of the vomeronasal fibers.

The question of the nervus terminalis and its relation to the vomeronasal nerves I shall not take up in the present paper as my studies have been restricted to mammalian forms which are not adapted to that problem. Important work in that direction has already been published (Herrick, '09; Sheldon, '09; Brookover, '10; Brookover and Jackson, '11; McKibben, '11). 


\section{MATERIAL AND METHODS}

The observations about to be reported were based in part on serial sections, stained by the Wiegert method, of the opossum and the rat, and in part on dissections of fresh and prepared specimens of one or more of the following species: opossum, bat, rat, rabbit, guinea pig, sheep, cat, dog and reptiles (snake and gila monster). Figs. 2 to 7 represent drawings made from such dissections. In both the rat and the opossum wax plate reconstructions were made to show the detail in shape and relative size of the accessory olfactory bulb.

For purposes of dissection it was found advantageous to immerse the specimen, after it had been divided just to one side of the median sagittal plane, in Müller's fluid to which had been added 5 per cent glacial acetic acid. After the specimen had been in this fluid from twelve to twenty four hours its component nerve fibers were found toughened and differentiated in color facilitating their identification. The dissection was done under water or weak alcohol with a binocular microscope. The first step in the procedure consisted in the removal of the nasal septum, thereby exposing the vomeronasal organ and the nerves arising from it. It is then easy to trace the nerves upward in the submucosa to where they terminate in the accessory olfactory bulb.

\section{PERSONAL OBSERVATIONS}

Concerning the microscopical appearances of the accessory olfactory bulb I have very little to add to the descriptions already given by Kölliker ('96) and Cajal ('11). In fig. 1, however, I am able to show the appearance as found in the opossum which constitutes a very favorable species for the study of thisstructure. This figure represents a transverse section through the caudal part of the olfactory bulb stained by the Wiegert method. The accessory olfactory bulb can be seen in the dorsal portion constituting a little more than half of the thickness of the brain wall. Like the olfactory bulb it consists of four layers: (1) superficial fiber layer, (2) layer of glomeruli, (3) layer of gray substance or molecular layer and (4) the granular layer. The 
vomeronasal nerve can be seen at the median border where it spreads out to form the superficial fiber layer. The glomeruli are smaller than those of the olfactory bulb and appear to be grouped in smaller and more irregular masses. The molecular layer differs in that the cells corresponding to the mitral cells

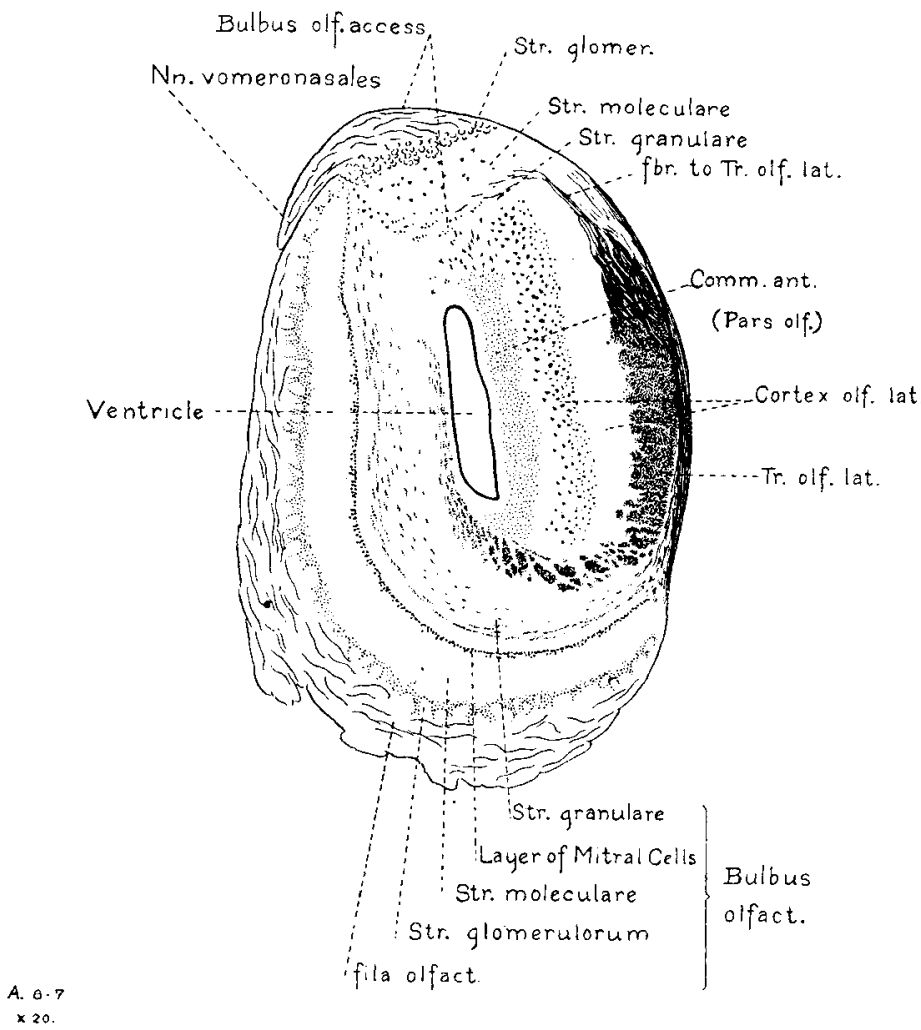

Fig. 1 A transverse section through the caudal part of the olfactory bulb of the opossum illustrating its relation to the accessory olfactory bulb and the termination of the vomeronasal nerves. From a Wiegert preparation (our series, Op. A., slide 8 , section 7). Magnified ten diameters.

are not arranged along a sharply marked line as in the olfactory bulb but are irregularly placed throughout the whole layer. The granular layer forms the innermost layer of the accessory olfactory bulb and projects with a convex surface 
toward the remainder of the bulb. Its constituent cells are clumped in characteristic islands from between which fibers can be seen emerging which pass lateralward to join the main lateral olfactory tract.

It will be noticed that the term olfactory bulb' is used in the sense as used by Kölliker, that is to include only: (1) stratum glomerulorum (with its fila olfactoria); (2) stratum moleculare (including the mitral cells); and (3), stratum granulare. 'Olfactory formation' is a term used by some writers for the same thing. It refers only to the cap-like mass covering in the olfactory evagination and does not include necessarily the fiber bundles coming to and going away from it. Thus in fig 1 the olfactory bulb forms only the ventral and median part of the section. The accessory bulb forms the dorsal part of the section, while the lateral half of the section is formed by a strand of fibers from the anterior commissure, by the bundles of fibers constituting the lateral olfactory tract and between these two a forward extention of the lateral olfactory cortex belonging to the pyriform lobe.

In describing the appearances of these structures as seen in the dissections each animal will be taken up separately. In most cases only one dissection was made and no attempt. was made to determine the amount of variation. Judging, however, from the comparison of the different ones it is evident that the variation is not great.

\section{Opossum}

The olfactory bulb of the opossum (fig. 2) extends horizontally forward beyond the hemisphere. It is ovoid in shape with a well defined oblique groove determining its junction with the short stout peduncle. The median surface is flattened against the bulb of the opposite side. The ventral part of this surface extends one-third of its length farther caudally than the lateral. The superior and lateral surfaces are comparatively smooth and convex. The anteroventral surface lies upon the concave dorsal aspect of the cribriform plate and receives the numerous large olfactory nerve filaments which spread out in a network 
of varying thickness over the entire surface of the olfactory bulb.

The accessory olfactory bulb presents an oval elevated surface lying on the dorsomedian aspect of the olfactory peduncle at the caudal margin of the olfactory bulb. It is separated from the olfactory bulb and peduncle by a shallow groove. The blunt rounded extremity of the frontal lobe of the cerebrum covers its caudal border.

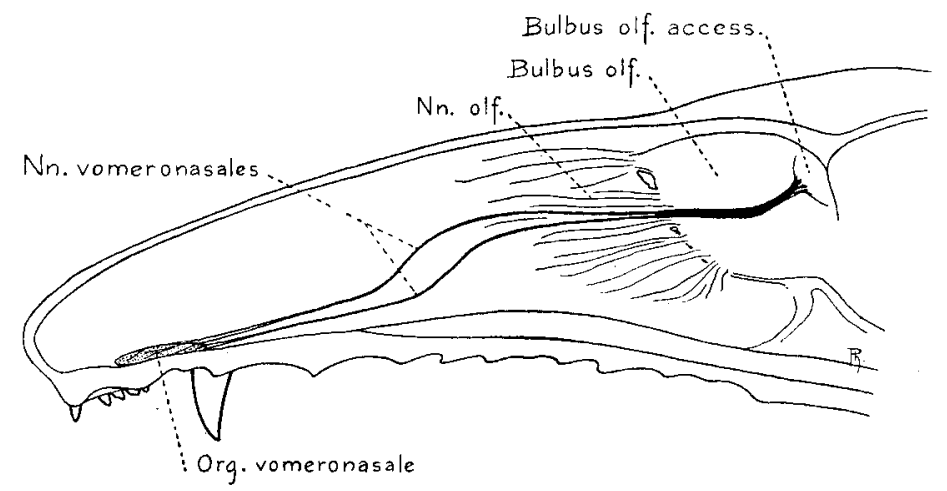

Fig. 2 Median section of the head of an opossum with the mandible and nasal septum removed to show the course and connections of the vomeronasal nerves. Natural size.

The vomeronasal nerves arise as a large number of fine filaments coursing obliquely upward and backward on the median wall of the vomeronasal organ. Immediately dorsal to the organ they unite to form two well defined nerves which course parallel to one another and horizontally backward in the submucosa of the much elongated septum to the cribriform plate. These nerves pass directly to the cribriform plate except for a short double curve in the region of the junction of the septal cartilage with the perpendicular plate of the ethnoid bone. After entering the cranium by separate foramina, accompanied by olfactory filaments, the two nerves unite and pass upward and backward over the median surface of the olfactory bulb to the anteromedian border of the accessory bulb where they spread out in a network over its surface. 


\section{Rat}

In its outer form the olfactory bulb of the rat (fig. 3) resembles that of the opossum. Its long axis, however, extends obliquely upward and forward instead of horizontally forward as in the opossum and as will be seen in the rabbit. It is partly covered in above and posteriorly by the frontal lobe of the cerebrum. The median surface is flattened against the opposite olfactory bulb, the dorsal and lateral surfaces are convex. The anteroventral surface lies upon the obliquely placed lamina cribrosa. The posterior border of the olfactory bulb is determined by an irregular oblique groove which sharply marks its junction with the olfactory peduncle.

The accessory olfactory bulb forms a small oval mass occupying a shallow fossa on the dorsal surface of the olfactory peduncle. It is slightly raised above the smooth surface of the peduncle and separated from it by a shallow groove. It is entirely hidden from view by the forward extention of the frontal lobe of the cerebrum, and in order to see it, it is necessary to remove a portion of the cerebrum as is shown in fig. 3 .

The vomeronasal nerves begin as a group of small filaments which arise from the ventral and median walls of the vomeronasal organ. These filaments curve around the median surface of the organ and leave its dorsal margin in four well defined nerve bundles. The more caudal two are somewhat larger, while the more oral two are more slender and show some tendency to plexus formation. These nerve bundles course dorsocaudally in the submucosa on the surface of the septum until they reach the lamina cribrosa. Here they enter the cranium by separate foramina accompanied by some of the olfactory filaments. After entering the cranium they unite on the median surface of the olfactory bulb into one nerve trunk which courses caudally to the caudal border of the bulb where it turns lateralwards to the accessory olfactory bulb. The nerve spreads out over the surface of the accessory bulb to form its superficial fiber layer. 


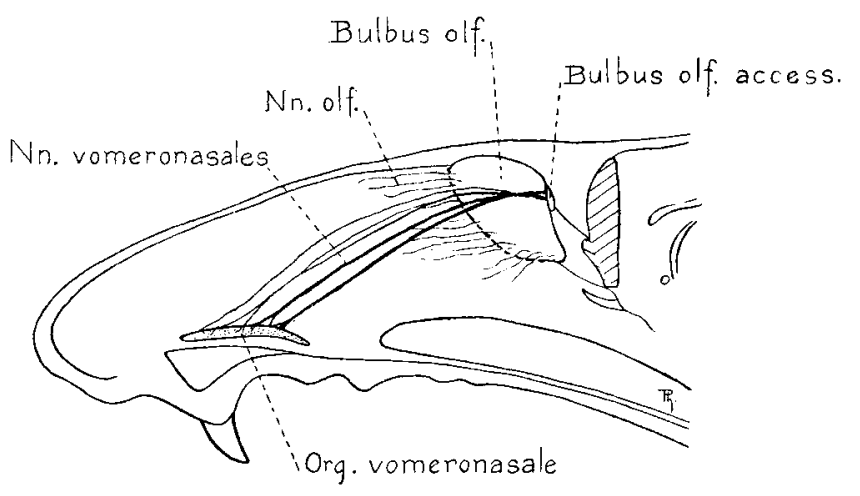

3

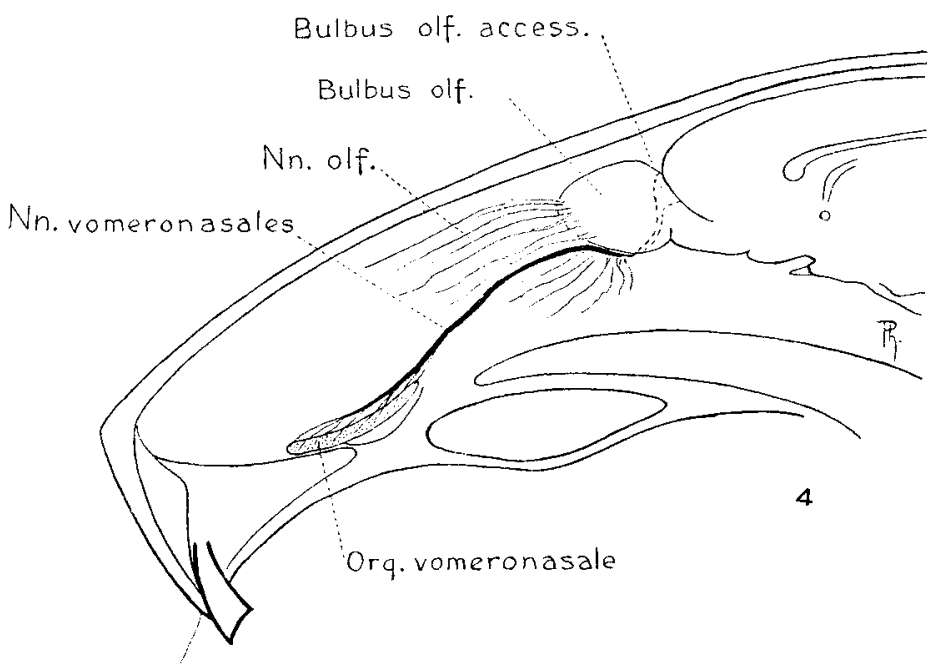

Fig. 3 A median section of the head of a rat with the mandible, the nasal septum and the anterior portion of the cerebrum removed to show the origin, course and termination of the vomeronasal nerves. Magnified two diameters.

Iig. 4 Median section of the head of a guinea pig showing the origin, course and termination of the vomeronasal nerves. The nasal scptum and mandible have been removed. Magnified two diameters. 


\section{Guinea pig}

The olfactory bulb of the guinea pig (fig. 4) resembles that of the opossum and the rabbit in extending directly forward so that the longest axis corresponds to the longitudinal axis of the brain. It thus happens that it is only partly covered in by the frontal lobe of the brain. The median surface of the bulb is the largest and flattened against the bulb of the other side. It extends about one third of its length farther caudally than the lateral surface. The anteroventral surface receives the olfactory filaments from the olfactory mucosa and lies upon the obliquely placed lamina cribrosa. The olfactory bulb is connected with the main mass of the brain by a short slender. peduncle.

The accessory olfactory bulb forms a small white hemispherical swelling on the dorsolateral aspect of the olfactory peduncle at the caudal margin of the olfactory bulb. It is circumscribed by a shallow groove which makes a sharp boundary between it and the olfactory bulb and peduncle. The forward extention of thefrontal lobe entirely obscures it from view when looked at directly from above. It may be clearly seen, however, in a lateral view of the brain.

As in the opossum and the rat the vomeronasal nerves arise by numerous filaments from the median surface of the vomeronasal organ. These filaments extend obliquely upward on the median surface of the organ and become assembled into a single trunk along its dorsal margin. From the posterior extremity of the organ the vomeronasal nerves continue as a single trunk dorsocaudally through the submucosa of the nasal septum to the lamina cribrosa through which they pass by a single foramen into the cranial eavity. Its course within the cranial cavity is different from that of all other mammals examined. Instead of passing upward on the median surface of the olfactory bulb, it takes a curved course on the upper surface of the cribriform plate around behind the more caudal olfactory filaments to reach the lateral surface of the olfactory bulb. Thus in the guinea pig the vomeronasal nerves, instead of reaching the acces- 
sory bulb by a median course, pass spirally under the olfactory bulb and enter the accessory bulb at its ventral and lateral borders.

\section{Rabbit}

In the rabbit (fig. 5) the olfactory bulb extends forward beyond the hemisphere. It is oval, compressed from side to side and its long axis lies in the horizontal plane. The posterior border is determined by an irregular, oblique, circular groove which indicates its union with the olfactory peduncle. The anteroventral surface receives the olfactory nerve filaments which spread out over the surface of the bulb in a thick network of

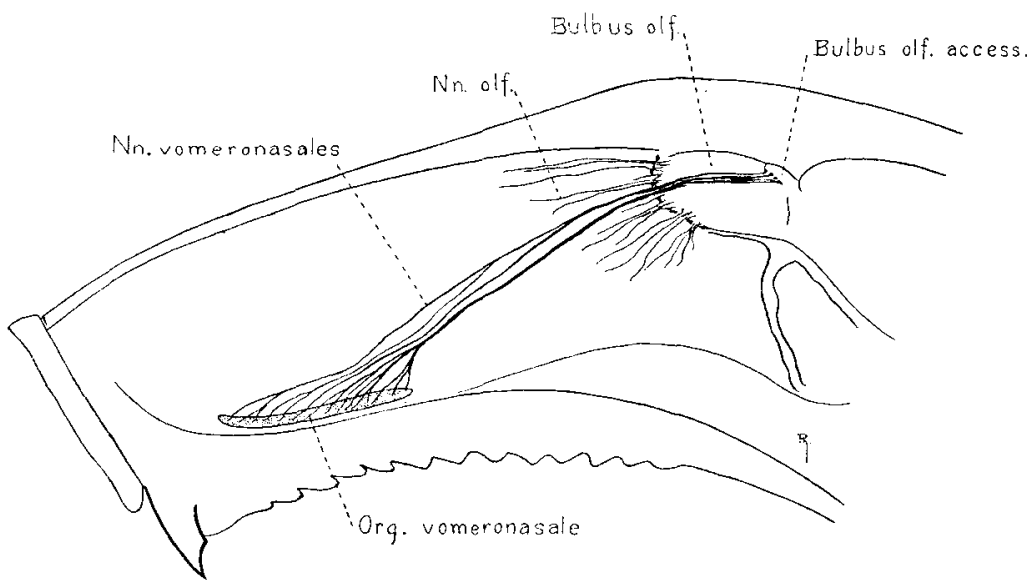

Fig. 5 A median section of the head of a rabbit showing the origin, course and termination of the vomeronasal nerves. The nasal septum and mandible have been removed. Natural size.

fibers. The median surface is flattened against the opposite olfactory bulb. It extends one-third of its length farther caudally than the lateral surface. The lateral and dorsal surfaces are convex and appear smoother than the others.

On removing the dorsal part of the cranium and meninges there can plainly be seen the accessory olfactory bulb lying between the caudal border of the olfactory bulb and the anterior rounded extremity of the frontal lobe of the cerebrum. It is 
a small structure producing an oval eminence on the dorsomedian aspect of the olfactory peduncle. The olfactory bulb is separated from it by an interveing portion of the olfactory peduncle.

The vomeronasal nerves arise by numerous fine filaments from the ventral parts of the median urface of the vomeronasal organ. From their origin they pass obliquely upward over this surface being joined by other fibers in their course. Along the dorsal margin of the organ they unite with one another to form about eight well defined nerve bundles. Here the two nerve bundles formed by the union of all the filaments from the posterior half of the organ unite into one large bundle which courses upwards and backwards through the submucosa of the septum to the lamina cribrosa. The remaining six nerve bundles which represent the filaments arising from the anterior half of the vomeronasal organ run parallel close to one another, and at about two thirds of the distance to the lamina cribrosa they unite into one trunk which continues its course to the cribriform plate. After passing through the same foramen the two nerve bundles unite and pass posterior on the median surface of the olfactory bulb. At about the middle of their course over the bulb the nerve divides into three nearly equal parts which continue an individual course to the posterior border of the bulb where they unite again and turn laterally to the anterior margin of the accessory bulb. Here the nerve spreads out to cover its surface with a plexiform layer of fibers. Thus in the rabbit the bundles forming the vomeronasal nerves are united in a single trunk only in one part of their course, and that is where they pass through the foramen in the eribriform plate. In the other regions they are grouped into between three and eight separate bundles. As in most of the animals examined the more caudal bundles have a tendency to be larger then the others.

\section{Sheep}

The olfactory bulb of the sheep (fig. 6) lies in a deep fossa on the cribriform plate so that it is hidden from view in a median sagittal section of the head. From above it is pressed forward 
by the frontal lobe of the brain which fits closely in its concave dorsocaudal surface (see dorsal view, fig. 6). The cribriform plate approaches a vertical position and the axis of the olfactory bulb forms an angle of about 130 degrees with the peduncle. Thus the ventral surface in which the olfactory nerves terminate is crowded upward and presents a convex surface that is perpendicular to the olfactory mucosal regions.

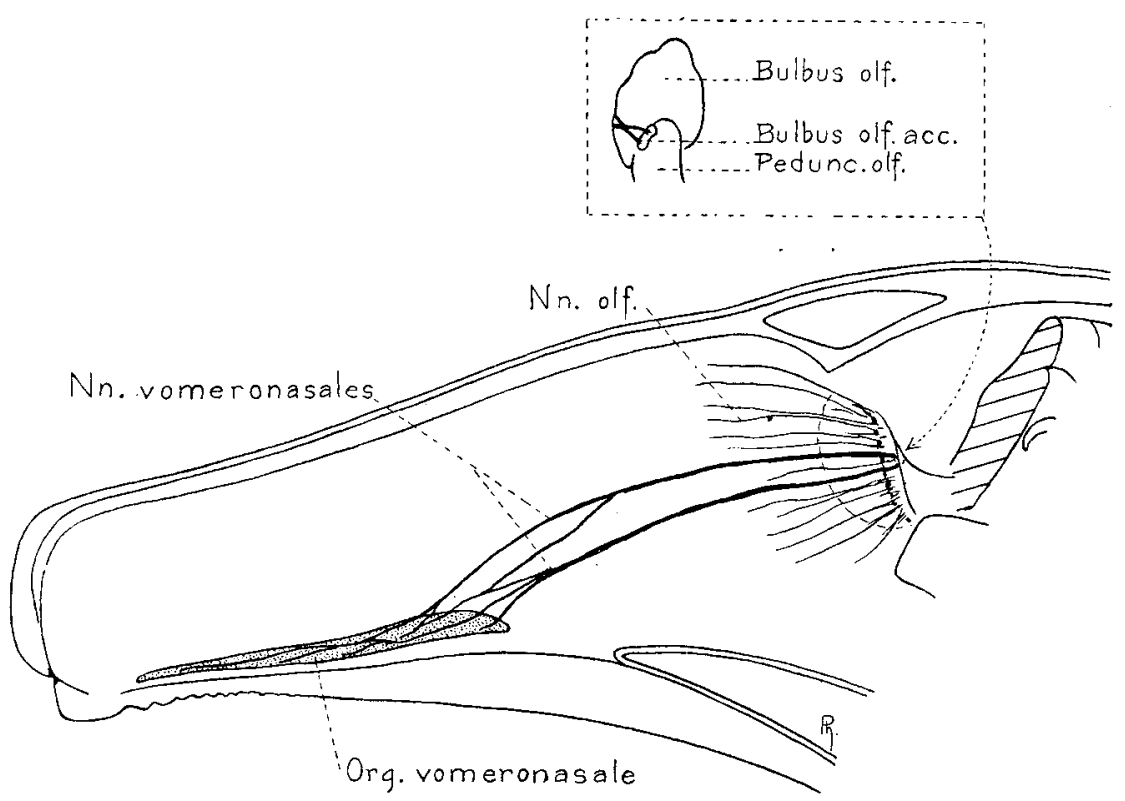

Fig. 6 Median section of the head of a sheep with the frontal lobe of the brain, the nasal septum and the mandible removed showing the origin and course of the vomeronasal nerves. A dorsal view of the olfactory bulb is shown above indicating the termination of the nerves. Two-thirds natural size.

The size and position of the accessory olfactory bulb is indicated in fig. 6 . It lies on the dorsal surface of the olfactory peduncle at the caudal margin of the olfactory bulb and is completely under cover of the frontal lobe of the brain. It forms an oval mass about twice as long as broad and is outlined by a shallow groove. Its posterior margin has an indentation which partly separates it into two lobes. 
The vomeronasal nerves arise by several small filaments from the anterior extremity of the large elongated vomeronasal organ. These filaments course in an oblique logitudinal direction on the median surface of the organ to its posterior extremity, increasing in size by the addition of other filaments. Here they leave as four well defined nerve trunks. In the first half of their course to the lamina cribrosa the nerves join one another in a plexiform manner and finally form two large nerve trunks which course to the cribriform plate. These two nerve trunks pass through separate foramina accompanied by olfactory nerve filaments. After entering the cranium they bend sharply around the dorsal margin of the olfactory bulb to reach its posterosuperior surface. Here they unite into one nerve which almost immediately divides again into two short, stout trunks, one going to each extremity of the accessory olfactory bulb to spread out over its surface.

\section{Cat}

Viewed from the median aspect the olfactory bulb of the cat has a quadrilateral outline with a long axis passing from above caudoventralward. It is compressed from side to side. The lateral and median surfaces are large. The.former lies against the concave bony wall of the brain case. The latter is flat and lies in apposition to the median surface of the olfactory bulb of the opposite side. The dorsal, caudal, ventral and oral surfaces are narrowed at the expense of the lateral and median. The dorsal surface is convex smooth and lies in contact with the anterior part of the vault of the cranium. The caudal surface is covered by the forward extention of the frontal lobe of the brain. From the ventral part of this surface the olfactory peduncle extends caudally to the main mass of the cerebrum. The convex ventral surface lies upon the floor of the anterior cranial fossa. The anterior surface lies against the obliquely placed lamina cribrosa and receives the olfactory nerves which spread out over the surface of the olfactory bulb.

The accessory olfactory bulb in the cat is about the same size as in the opossum. It is oval slightly elevated from the sur- 
rounding surface of the dorsomedian aspect of the olfaetory peduncle at the caudal margin of the olfactory bulb.

The vomeronasal nerves arise by numerous filaments from the ventral border of the vomeronasal organ. They course obliquely upward and backward on its median wall and leave the dorsal border as two small trunks. These nerve trunks continue the dorsocaudal course to the lamina cribrosa where they enter the cranium by separate foramina. They unite immediately after entering the cranium. The single nerve trunk thus formed extends upward and backward on the median surface of the olfactory bulb to its caudal border. Here it turns sharply lateralward over the posterior surface to reach the anterior margin of the accessory olfactory bulb.

\section{Dog}

The large quadrilateral shaped olfactory bulb of the dog (fig. 7 ) is compressed into its particular shape by the frontal pole of the cerebrum on one side and the framework of the nasal passages on the other. The dorsocaudal surface is concave and moulded to the anterior extremity of the frontal lobe. The olfactory peduncle extends backward from the ventrolateral part of this surface. The anteroventral surface lies against the obliquely placed cribriform plate. It receives the olfactory nerves which spread out in a thick network over the surface of the olfactory bulb. The median thickened border of the olfactory bulb is separated from the opposite bulb by the dorsal extension of the perpendicular plate.

The accessory olfactory bulb is smaller in the dog than in the rabbit, rat and guinea pig. It forms a small oval elevation on the median surface of the olfactory peduncle at the caudal margin of the olfactory bulb. It may be seen only upon careful removal of the pia mater.

The vomeronasal nerves arise by a large number of filaments from the median surface of the vomeronasal organ. These filaments unite in such a manner that eight nerve strands leave the dorsal border of the organ. Soon after leaving they unite to form four large bundles. The four bundles turn caudally 
and course through the submucosa of the nasal septum to the cribriform plate. They enter the cranium by two openings and then unite into a single nerve trunk, which passes around the median thickened border of the olfactory bulb, where, turning lateralward on its dorsal surface the nerve separates out in a network of fibers which terminates in the accessory olfactory bulb. On the dorsal surface of the olfactory bulb the vomeronasal nerves are closely applied to the layer of fila olfactoria.

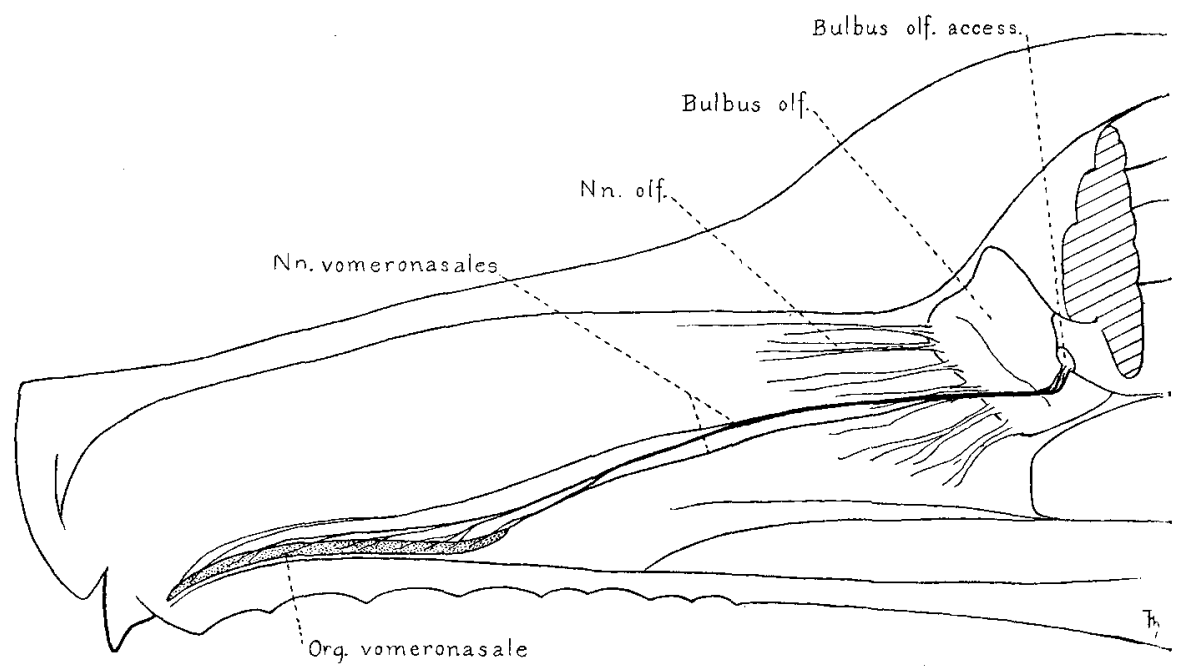

Fig. 7 A median section of the head of a dog with the frontal lobe of the brain, the nasal septum and mandible removed showing the origin, course and termination of the vomeronasal nerves. Natural size.

It may be mentioned that what seemed to be a small nerve bundle left the group of vomeronasal fibers near the accessory olfactory bulb and passed caudalward to the median surface of the brain and terminated in the ventral part of the precommissural area. This would suggest the nervus terminalis of Pinkus. This, however, was only found in one specimen and nothing definite can be said of it until it is more carefully worked out. 


\section{Reptiles}

It is beyond the purpose of the present paper to trace the changes in the vomeronasal nerves in submammalian forms. However, dissections were made of the snake and gila monster (heloderma suspectum). In the former the vomeronasal nerves form two large bundles which pass backward on the median surface of the olfactory evagination and finally unite and then terminate in a ganglion mass situated on the dorsal and median surface of the evagination, which is nearly as large as the olfactory formation itself. This corresponds closely to the conditions described by Herrick ('93). In the gila monster the vomeronasal nerves terminate in a similar ganglion mass though it is not so large. Evidently these ganglion masses corresponds to the accessory olfactory bulb of mammals.

\section{SUMMARY}

It will be seen from the foregoing descriptions of the accessory olfactory bulb that it is a ganglionic mass for the reception of fibers from the vomeronasal organ of Jacobson and that centrally it gives off fibers that join the lateral olfactory tract. It is entirely separate from the olfactory bulb, though it is contiguous to it, being always situated on its dorsocaudal surface. Its size varies directly with the size of the vomeronasal organ.

It is evident that Balogh's 'Jacobson's hill', Smith's 'Ganglion of Jacobson's organ', Döllkin's 'Ganglion terminale', and probably also Herricks's 'median ganglion mass in reptiles' are the same thing as the accessory olfactory bulb.

The olfactory nerve filaments may be divided into two distinct groups; (a) ordinary olfactory fibers, terminating in the olfactory bulb; and (b) vomeronasal fibers, terminating in the accessory olfactory bulb. It is probable that a third group may be added to include the nervus terminalis, the description of whose central connections are entirely different from either of the first two groups.

Throughout the text of this paper an effort has been made to conform to the nomenclature that is at present in most general 
use. I would suggest, however, the substitution of the term 'tuberculum vomeronasale' in the place of 'bulbus olfactorius accessorius'. We would then have the vomeronasal organ, the vomeronasal nerve filaments and the vomeronasal tubercle as the component parts of this apparatus.

In conclusion the writer takes pleasure in-acknowledging his indebtedness to Professor Streeter whose constant advice has facilitated the completion of this study.

\section{BIBLIOGRAPHY}

BALOGH, C. 1860 Uber das Jacobson'sche Organ des Schafes. Sitzungsb.

d. Kais. Akad, d. Wissensehaften in Wien, Bd. 42, S. 449.

BAWDEN, JR., H. H. 1894 The nose and Jacobson's organ with especial reference to Amphibia. Jour. Comp. Neur., vol. 4, p. 139.

Вroокоver, C. 1910 The olfactory nerve, the nervus terminalis and the pre-optic sympathetic system in Amia calva, 1. Jour. Comp. Neur., vol. 20, p. 49 .

Brookover, C., AND Jackson, T. S. 1911 The olfactory nerve and the nervus terminalis of Ameiurus. Jour. Comp. Neur., vol. 21, p. 261.

v. Brunn, A. 1892 Die Endigung der Olfactoriusfasern im Jacobson'sche Organe des Schafes. Archiv. Mikro. Anat. Bd. 39, S. 651.

CaJaL, S. R. 1911 Histologie du systeme nerveaux. T. 2, p. 670.

DEVRIEs, E. 1905 Note on the ganglion vomeronasale. K. Akad. van Wetenschappen te Amsterdam, vol 7, p. 704.

DöLLKIN, A. 1909 Ursprung und Zentren des Nervus terminalis. Monatsschr. f. Psych. u. Neur. Erg. Heft. Bd. 26, S. 10.

Edinger, L. 1908 Vorlesungen über den Bau der nervosen Zentralorgane, Bd. 2, S. 253.

Ganser, S. 1882 Vergleichend anatomische Studien uber das Gehirn des Maulwurfs. Morph. Jahrb., Bd. 7, S. 645.

v. Gudden, B. 1870 Experimentaluntersuchung über das peripherische und centrale Nervensystem. Archiv. f. Psych., Bd. 2, S. 699.

HerRICK, C. L. 1893 Topography and histology of the brain of certain reptiles. Jour. Comp. Neur., vol. 3, p. 77.

Herrick, C. J. 1909 The nervus terminalis (nerve of Pinkus) in the frog. Anat. Rec., vol. 3, p. 257.

1910 The morphology of the forebrain in amphibia and reptilia. Jour. Comp. Neur., vol. 20, p. 413. 
KLein, E. 1881 a Contributions to the minute anatomy of the nasal mucous membrane. Quart. Jour. Micro. Sci., vol. 21, p. 103.

$1881 \mathrm{~b}$ A further contribution to the minute anatomy of the organ of Jacobson in the guinea pig. Quart. Jour. Micro. Sci., vol. 21, p. 219.

$1881 \mathrm{e}$ The organ of Jacobson in the rabbit. Quart. Jour. Micro. Sci., vol 21, p. 549 .

1882 The ofgan of Jacobson in the dog. Quart. Jour. Micro. Sci., vol. 22 , p. 229.

Kölliker, A. 1896 Gewebelehre des Menschen, Bd. 2, S. 694.

Lenнossek, M. 1892 Die Nervenursprunge und-Endigung im Jacobson'schen Organ des Kaninchens. Anat. Anz., Bd. 7, S. 629.

MoKibren, P. S. 1911 The nervus terminalis in urodele Amphibia. Jour. Comp. Neur., vol. 21, 0. 261.

Minalkovics, V. 1898 Nasenhöle und Jacobson'sches Organ. Anat. Hefte Bd. 11, S. 42.

PIANA, G. P. 1882 Contribuzioni alla conoscenza della strutture e della funzione dell' organo di Jacobson. Bologna 1880. Deusch. Zeitsch. f. Tiermedizin, Bd. 7, S. 325 .

Pinkus, F. 1894 Uber einen noch nicht beschriebenen Hirnnerven des Protopterus annectens. Anat. Anz. Bd. 9, S. 562.

READ, E. A. 1908 A contribution to the knowledge of the olfactory apparatus in dog, cat and man. Amer. Jour. Anat., vol. 8, p. 40.

Sheldon, R. E. 1909 The nervus terminalis in Teleosts. Anat. Rec., vol. 3 , p. 257.

Sмiтh, G. Eliotт 1895 Jacobson's organ and the olfactory bulb in ornithorhynchus. Anat. Anz. Bd. 11, S. 161.

1897 The brain of a fetal ornithorhynchus. Quart. Jour. Micro. Sci., vol 39, p. 197.

ZIenen, Th. 1897 Semon: Zoologische Forschungsreisen Bd. 3. Monotremen und Marsupials, 2 S. 726. 